\title{
Impact of Education on Knowledge and Practice of Kala Azar Preventive Measures among Seasonal and Migrant Agricultural Workers in Northwest Ethiopia
}

\author{
Mekuriaw Alemayehu, ${ }^{1 \star}$ Lucy Paintain, ${ }^{2}$ Cherinet Adera,${ }^{3}$ Resome Berhe,${ }^{4}$ Abebaw Gebeyehu, ${ }^{5}$ Zemichael Gizaw, ${ }^{1}$ \\ Merce Herrero, ${ }^{3}$ Abate Mulugeta Beshah, ${ }^{6}$ Margriet Den Boer, ${ }^{7}$ Adane Nigusie, ${ }^{4}$ Meseret Alem, ${ }^{8}$ Enyew Yechale, ${ }^{9}$ and \\ Dia-Eldin A. Elnaiem ${ }^{10}$
}

\begin{abstract}
${ }^{1}$ Department of Environmental Health and Safety, Institute of Public Health, College of Medicine and Health Sciences, University of Gondar, Gondar, Ethiopia; ${ }^{2}$ Department of Disease Control, Faculty of Infectious and Tropical Diseases, London School of Hygiene \& Tropical Medicine, London, United Kingdom; ${ }^{3}$ KalaCORE Country Office, Addis Ababa, Ethiopia; ${ }^{4}$ Department of Health Education and Behavioral Sciences, Institute of Public Health, College of Medicine and Health Sciences, University of Gondar, Gondar, Ethiopia; ${ }^{5}$ Department of Reproductive Health, Institute of Public Health, College of Medicine and Health Sciences, University of Gondar, Gondar, Ethiopia; ${ }^{6}$ WHO Country Office, Addis Ababa, Ethiopia; ${ }^{7}$ KalaCORE Coordinator for East Africa, London, United Kingdom; ${ }^{8}$ Department of Immunology and Molecular Biology, School of Biomedical and Laboratory Science, University of Gondar, Gondar, Ethiopia; ${ }^{9}$ KalaCORE Regional Office, Bahir Dar, Ethiopia; ${ }^{10}$ Department of Natural Sciences, University of Maryland Eastern Shore, Princess Anne, Maryland
\end{abstract}

\begin{abstract}
Kala azar occurs among seasonal and migrant agricultural workers in northwest Ethiopia and accounts for almost $60 \%$ of the disease burden in the country. We conducted a quantitative study on the level of knowledge and practice of this vulnerable group in relation to kala azar transmission and acceptability of its vector control tools. A total of 403 workers were randomly selected from eight farms using a purposive sampling technique. Knowledge and practice scores were calculated based on 12 and 9 core questions, respectively. Binary logistic regression was used to identify factors associated with knowledge and practice. A large gap in knowledge of the disease and the vector was evident with $61.8 \%, 24.6 \%$, and $13.6 \%$ of the workers having poor, moderate, and good levels of knowledge scores, respectively. Similarly, $95 \%$ of the seasonal workers reported poor level of use of protective measures against the bite of the sand fly vector. Good level of knowledge about kala azar and its sand fly vector was statistically associated with formal education (adjusted odds ratio $[\mathrm{AOR}]=2.11 ; 95 \% \mathrm{Cl}=1.17,3.80 ; P<0.05)$ and previous exposure to health education $(\mathrm{AOR}=4.72$; $95 \% \mathrm{Cl}=1.99,11.16 ; P<0.001)$. Despite poor current knowledge and practice, a large proportion of the study participants showed interest in using vector control tools if made available, with $78 \%$ of the seasonal and migrant workers expressing some willingness to pay for different measures that can protect against sand fly bites. Therefore, we strongly recommend that comprehensive health education and vector control programs should be provided to these workers.
\end{abstract}

\section{INTRODUCTION}

Visceral leishmaniasis (VL) (also known as kala azar), caused by the parasite Leishmania donovani, is an important vector-borne disease in Ethiopia, with an annual incidence of $2,000-4,500$ cases. $^{1-3}$ Almost $60 \%$ of these cases are known to occur among seasonal and migrant agricultural workers in the Metema-Humera lowlands in the northwest region of the country. ${ }^{4}$

Up to 500,000 migrant laborers annually visit the MetemaHumera lowlands, mainly from the surrounding Amhara and Tigray highland areas, for weeding and harvesting of sesame, sorghum, and cotton, mostly between June and October. ${ }^{5}$ These migrant and seasonal workers are at a high risk of acquiring $\mathrm{VL}$ infection, ${ }^{6-8}$ especially considering the extremely poor and harsh conditions that they endure during their work in the farms. Furthermore, it is believed that seasonal and migrant workers who are infected by L. donovani may also play a role in spreading the infection to the highlands when they return. ${ }^{9} \mathrm{~A}$ case in point is the endemic foci of VL in Libo Kemkem and Fogara districts, where between 2003 and 2005, a severe epidemic of the disease resulted in 2,450 primary cases. The parasite is thought to have been introduced by seasonal and migrant workers who acquired the infection in lowland farms in the Metema-Humera area. ${ }^{10}$ The highland areas, which were previously known to be free

*Address correspondence to Mekuriaw Alemayehu, Department of Environmental Health and Safety, Institute of Public Health, College of Medicine and Health Sciences, University of Gondar, P.O. Box 196, Gondar, Ethiopia. E-mail: mekuriaw14@gmail.com of the infection, have then continued to be low incidence endemic areas.

Prevention of kala azar transmission to seasonal and migrant workers in lowland agricultural farms of northwest Ethiopia poses a formidable challenge to disease controllers. This is partly because of the lack of control measures that can be applied on a community basis on this highly mobile population. Under such situations, the most feasible control measures are personal protection tools, which involve a high level of compliance that in turn depends on the behavior of the users and their awareness of the problem.

Little is known about the level of kala azar knowledge and socioeconomic and behavioral factors that affect the exposure of seasonal and migrant workers to sand fly bite and acceptability of vector control tools. Although two previous studies were conducted on knowledge, attitudes, and practice in relation to kala azar in northwest Ethiopia, the investigations were restricted to resident populations and did not address the exposure of seasonal and migrant workers to sand fly bites and their acceptability of control tools. ${ }^{11,12}$

A number of studies attempted to determine kala azar risk factors in East Africa. ${ }^{13-15}$ Most of the information we currently know about behavioral factors that increase or decrease the risk of infection with kala azar in northwest Ethiopia were obtained in a single case-control study conducted to identify risk factors associated with kala azar among resident and migrant populations in the Humera area. ${ }^{16}$ In this study, the authors found that sleeping under an acacia tree, indicators of poverty, and lower educational status were associated with an increased risk in both populations. Strong protective effects were observed for bed net use among migrants; the risk 
associated with HIV status was borderline significant, and sleeping near dogs was associated with a 7-fold increased risk. The study recommended that preventive strategies should focus on encouraging bed net use, especially among migrant workers who have no fixed shelters to stay in.

In this study, we investigated the existing levels of knowledge of kala azar and its vector control among seasonal and migrant agricultural workers in northwest Ethiopia. We also assessed current practice and behavior that could affect exposure to the infection and determined the acceptability and willingness to pay (WTP) for old and new tools that can provide protection from sand fly bites.

\section{METHODS}

Study design. The study adopted a cross-sectional design in two surveys conducted during weeding (June-July) and harvesting operations (September-November, 2017) in farms employing large numbers of seasonal and migrant workers in Abdurafi and Metema areas.

Study area and setting. West Armachiho district (north Gondar administrative zone, northwest Ethiopia) is located about $250 \mathrm{~km}$ from Gondar town. The 2007 Ethiopia Population and Housing Census Report estimates the residents of West Armachio woreda to be 35,486 people, of whom 19,517 are males and 15,969 are females. The region is mainly agricultural, where a total of 125,475 hectares of land are used to cultivate sesame, sorghum, and other types of crop. Seasonal/migrant workers participate in different farm activities during weeding and harvesting operations.

Metema district (north Gondar administrative zone, northwest Ethiopia) is located $896 \mathrm{~km}$ from the capital city Addis Ababa. The total area of this woreda (locality) is 440,085 hectares, and the altitude is from 550 to $1600 \mathrm{~m}$ above sea level. The mean annual temperature ranges between 36 and $45^{\circ} \mathrm{C}$, and the average annual rain fall is $700-900 \mathrm{~mm}$. More than 25,000 seasonal workers participate in different farm activities during weeding and harvesting operations. Sesame, maize, and cotton are the common crops in the areas.

Source and study population. The study participants were recruited from the seasonal or migrant workers who arrived to conduct agricultural activities in Metema and Abdurafi farms during July-October 2017. The main inclusion criterion was any seasonal or migrant worker, older than 18 years, who had been working in selected farms for not more than three years. The main exclusion criteria were residence in the lowland for more than 3 years and any current illness that could affect the participation of the worker in the study.

Operational definitions. Seasonal worker. A person who is a resident of the highlands and who comes to the lowlands to work in the agricultural farms for one agricultural season only (June-October), without staying during the dry season (November-May).

Migrant worker. A person who is a resident of the highlands and who comes to the lowlands to work in the agricultural farms for one agricultural season (June-October) and stays in the lowlands during the previous or subsequent dry season for one year or more, but without establishing residence.

Sample size determination. The sample size was calculated using a single population proportion formula for knowledge and practice of seasonal workers separately to choose the representative one with the following assumptions: level of knowledge on kala azar $=89.4 \%,{ }^{11}$ level of practice $=50 \%(a$ conservative estimate due to the absence of similar studies), $95 \% \mathrm{Cl}, 5 \%$ margin of error, and 5\% nonresponse rate. The calculated sample size for knowledge and practice was 154 and 403, respectively. The larger more conservative sample size of 403 seasonal workers was then used for the study.

Sampling techniques. Before the data collection, a census of all farms in the study area was undertaken. A purposive sampling technique was used to select 8 farms from the total of 596 farms on the list. Based on the size of the farms and the number of workers they have employed to run the agricultural activities, we purposively selected four large-size farms and four small-size farms. The study subjects were selected using a computer-generated simple random sampling technique: identification numbers of rosters of seasonal workers from the selected farms, obtained from farms' daily attendance sheets, were entered into a random number generator that was used to randomly identify individuals to be enrolled as study participants.

Data collection procedures. Data were collected using a structured interviewer-administered pretested questionnaire. The English version questionnaire was adapted from similar credible literatures and translated into Amharic, the local language, by three independent investigators, who then agreed on a consensus version of the translation. The questionnaire comprised five parts: 1) socioeconomic information, 2) knowledge questions, 3) practice questions, 4) behavioral risk factor questions, and 5) WTP questions. A total of six environmental health and health promotion professionals and four behavioral epidemiology specialists participated as enumerators and field supervisors, respectively. Before the survey, the interviewers and supervisors took a 3-day training on the contents of the questionnaire, methods of data collection, approaches of interview, and data quality and ethical issues. After piloting, the research team conducted the data collection in the selected farms. Data completeness and quality were monitored in the field on a daily basis.

Measurement of outcome variables. Knowledge and practice, the primary and secondary outcome variables of this study, were defined based on Bloom's cutoff points. ${ }^{14} \mathrm{~A}$ total of 12 yes/no questions were included in the questionnaire to measure knowledge of kala azar. A score of 1 was given for each correct response and 0 for an incorrect response. Based on the total score, the level of knowledge was classified into "low-level knowledge" (less than 59\%), "moderate-level knowledge" (60-79\%), and "high-level knowledge" (80-100\%). Similarly, a total of nine practice questions were included to assess the level of practice. A score of 1 was given for each correct response and 0 for each incorrect response. The level of practice was classified into poor level (less than 59\%), fair level (60-79\%), and good level (80-100\%). ${ }^{14}$

Data processing and analysis. Double data entry was performed using EPI-INFO version 7.0. Validated data were exported into statistical package for social sciences version 20 for statistical analysis. For most variables, data were presented using frequencies, percentages, mean, median, and SD. Univariable binary logistic regression analysis was then used to explore potential predictors of a good level of knowledge or a good level of practice. Variables with a $P$-value less than 0.2 in the univariable analysis were included in the final multivariable binary logistic regression models. Variables that had a significant association with knowledge and practice 
after controlling the possible effect of confounders were identified on the basis of an adjusted odds ratio (AOR) with $P<0.05$.

Ethical approval and consent to participate. The study participants were included after explaining to them the detailed objective of signing the written informed consent agreement. Participants were informed of their rights to withdraw from the study at any stage or to restrict their data from the analysis. We planned to refer any suspected cases of kala azar or other diseases to nearby health centers for full diagnosis and treatment. No such case was encountered during the surveys. The protocol and the informed consent were approved by Independent Review Boards of the University of Gondar and London School of Hygiene and Tropical Medicine (LSHTM). Confidentiality of all private information was guaranteed. To ensure privacy of data, the information was identified using codes, instead of participants' names. Hard copies of questionnaires and transcripts were kept securely in the office of the principal investigator. Any electronic files were kept on a password-protected computer.

\section{RESULTS}

Sociodemographic information of the study participants. A total of 403 seasonal workers participated in the study with a 100\% response rate. Almost all, 398 (98.8\%), of the participants were males (Table 1). Majority of the study participants $(363,90.1 \%)$ were seasonal workers, and the remaining $(40,9.9 \%)$ were migrant workers. The age of the workers ranged from 14 to 70 years, with two hundred fortyone $(59 \%)$ of them younger than 25 years. The median age was 22 years, and the interquartile range was 20-28 years. The overwhelming majority of the participants were orthodox Christians by their religion $(398,98.8 \%)$ and Amhara by their ethnic group (394, 97.8\%). Two-thirds (268, 66.5\%) of the study participants were single by their marital status. Two hundred thirty-six (59.1\%) of the seasonal workers had received some formal education. One hundred forty-five (36.3\%), 235 (58.3\%), and 195 (49.6\%) workers reported that they received less than 20,80, and 100 Ethiopian birr per day $(0.74,2.96$, and 3.70 USD per day, respectively) during farmland preparation, weeding, and harvesting seasons, respectively (Table 1 ).

Schedules of farm visiting and agricultural activities of the study participants. Around three-quarters of the interviewed seasonal workers came to the lowlands for weeding (310, 76.9\%) and a similar number for harvesting (306, 75.9\%), whereas half $(219,50.1 \%)$ of them stayed for both weeding and harvesting (Table 2). The great majority, 335 (83.1\%), of the seasonal workers were engaged in agricultural activities from June to October. Two hundred eighty-one (54.1\%) of the respondents stayed for more than 3 weeks in one farming season. Two hundred forty-five $(60.8 \%)$ of the study participants reported that they had been visiting the farm area for seasonal work for 2 or more years, and $256(63.5 \%)$ of the workers had visited the lowland farm area three or more times in the previous 3 years (Table 2).

Level of knowledge. Responses to the 12 core questions on knowledge of kala azar and its vector are provided in Supplemental Table 1. The median score (percent) of the 403 participants who showed poor, moderate, or good level of knowledge of kala azar and its vector was $58.3 \%$ (IQR =
TABLE 1

Sociodemographic characteristics of seasonal/migrant workers $(n=$ 403) enrolled in a study on knowledge and acceptability of sand fly control measures in Abdurafi-Metema lowlands of northwest Ethiopia, 2017

\begin{tabular}{|c|c|c|}
\hline Variable & Frequency & $\%$ \\
\hline \multicolumn{3}{|l|}{ Gender $(N=403)$} \\
\hline Male & 398 & 98.8 \\
\hline Female & 5 & 1.2 \\
\hline \multicolumn{3}{|l|}{ Age (years) $(N=403)$} \\
\hline$<25$ & 241 & 59.8 \\
\hline $25-34$ & 115 & 28.5 \\
\hline $35-44$ & 32 & 7.9 \\
\hline$\geq 45$ & 15 & 3.7 \\
\hline \multicolumn{3}{|l|}{ Religion $(N=403)$} \\
\hline Orthodox Christian & 398 & 98.8 \\
\hline Muslim & 5 & 1.2 \\
\hline \multicolumn{3}{|l|}{ Ethnicity $(N=403)$} \\
\hline Amhara & 394 & 97.8 \\
\hline Tigray & 8 & 2.0 \\
\hline Oromia & 1 & 0.2 \\
\hline \multicolumn{3}{|c|}{$\begin{array}{l}\text { Kala azar endemicity at permanent } \\
\text { residence/place of residence }(N=400)\end{array}$} \\
\hline Lowland endemic areas & 23 & 5.8 \\
\hline Highland non-endemic areas & 377 & 94.2 \\
\hline \multicolumn{3}{|l|}{ Marital status $(N=403)$} \\
\hline Single & 268 & 66.5 \\
\hline Married & 130 & 32.3 \\
\hline Divorced & 5 & 1.2 \\
\hline \multicolumn{3}{|l|}{ Educational status $(n=399)$} \\
\hline No formal education & 163 & 40.9 \\
\hline Formal education & 236 & 59.1 \\
\hline \multicolumn{3}{|c|}{$\begin{array}{l}\text { Money paid per day at farm preparation } \\
(\text { ETB) }(N=400)\end{array}$} \\
\hline$<20$ & 145 & 36.3 \\
\hline$\geq 20$ & 255 & 63.8 \\
\hline \multicolumn{3}{|l|}{$\begin{array}{l}\text { Money paid per day at weeding (ETB) } \\
(N=292)\end{array}$} \\
\hline$<80$ & 235 & 80.5 \\
\hline$\geq 80$ & 57 & 19.5 \\
\hline$<100$ & 195 & 49.6 \\
\hline$\geq 100$ & 198 & 50.4 \\
\hline \multicolumn{3}{|c|}{$\begin{array}{l}\text { Income in the farm compared with home } \\
\qquad(N=401)\end{array}$} \\
\hline More & 196 & 48.9 \\
\hline Similar & 107 & 26.7 \\
\hline Less & 98 & 24.4 \\
\hline
\end{tabular}

33.3\%, 75.0\%), 249 (61.8\%), 99 (24.6\%), and 55(13.6\%), respectively (Supplemental Table 1). The respondent's most common source of kala azar information came from friends or relatives who had been sick with the disease $(40.8 \%)$ (Figure 1). Only $20.4 \%$ of the respondents received health education on kala azar and its vector. A similar proportion of the participants $(21.8 \%)$ learned about the disease from friends and/or other people surrounding them.

Accuracy of knowledge of seasonal and migrant workers on kala azar symptoms and transmission. Just less than one-fifth $(18.4 \%, 74 / 403)$ of seasonal workers reported extended fever, splenomegaly (locally named "Guwaqua"), and weight loss as the signs and symptoms of kala azar disease, and just more than $40 \%(43.2 \%, 174 / 403)$ of the workers said that kala azar causes pain and discomfort. A similar proportion $(45.9 \%, 185 / 403)$ reported that kala azar disease is endemic in lowlands. A quarter $(25.5 \%, 102 / 403)$ of the seasonal workers 
TABLE 2

Schedule of agricultural activities and place of origin of seasonal/migrant workers enrolled in a study on knowledge and acceptability of sand fly control tools in lowlands of northwest Ethiopia, 2017

\begin{tabular}{|c|c|c|}
\hline Variable & Frequency & $\%$ \\
\hline \multicolumn{3}{|l|}{$\begin{array}{l}\text { For which agricultural seasons you stayed } \\
\text { in this farmland* }\end{array}$} \\
\hline Land preparation & 116 & 28.8 \\
\hline Weeding & 310 & 76.9 \\
\hline Harvesting & 306 & 75.9 \\
\hline Land preparation and weeding & 112 & 25.6 \\
\hline Weeding and harvesting & 219 & 50.1 \\
\hline $\begin{array}{l}\text { Land preparation, weeding, and } \\
\text { harvesting }\end{array}$ & 106 & 24.3 \\
\hline \multicolumn{3}{|l|}{ Seasons of the year working in the farm } \\
\hline June-October & 335 & 83.1 \\
\hline November-May & 24 & 6.0 \\
\hline All year long & 40 & 9.9 \\
\hline \multicolumn{3}{|l|}{$\begin{array}{l}\text { Weeks stayed in the farm during the } \\
\text { current season }\end{array}$} \\
\hline$<3$ & 184 & 47.7 \\
\hline$\geq 3$ & 281 & 54.1 \\
\hline \multicolumn{3}{|l|}{ Number of years visiting this farmland } \\
\hline$<2$ & 151 & 37.5 \\
\hline$\geq 2$ & 245 & 60.8 \\
\hline \multicolumn{3}{|c|}{$\begin{array}{l}\text { Frequency of visiting the farm in the last } 3 \\
\text { years }\end{array}$} \\
\hline$<3$ times & 147 & 36.5 \\
\hline$\geq 3$ times & 256 & 63.5 \\
\hline
\end{tabular}

perceived that kala azar disease is transmitted by an insect bite (Table 3).

Knowledge about characteristics of sand fly. One-tenth, $41(10.2 \%)$, of the seasonal workers said that a sand fly is larger than a mosquito, and only $8.9 \%$ (36/403) of the workers correctly identified sand fly from a collection of pictures. One hundred ninety-three (47.9\%, 193/403), 216 (53.6\%, 216/ $403)$, and $143(35.5 \%, 143 / 403)$ of seasonal workers reported that sand fly actively bites in the evening, during the early rainy season (June-July), and near acacia trees, respectively (Table 4).

Knowledge about prevention measures. Figure 2 presents the responses of the study participants on their knowledge of the possible measures that can be taken to protect themselves from sand fly bites. The majority $(70.2 \%, 283 / 403)$ of the seasonal workers said that utilization of insecticidetreated nets (ITNs) could prevent sand fly bites. One hundred twenty $(29.8 \%, 120 / 403)$ workers reported that they did not know any possible prevention measures.

Current practice of control measures that can reduce exposure to sand fly bites. The median score among the 403 interviewed seasonal workers across the 9 kala azar practice questions was 22.2\% (IQR = 22.2\%, 33.3\%) (Supplemental Table 2); almost all (95\%, 383/403) of the seasonal workers reported a poor level of protective practice against kala azar, with only $3.5 \%(14 / 403)$ and $1.5 \%(6 / 403)$ of the seasonal workers reporting fair and good levels of practice, respectively. More than $40 \%(42.7 \%, 172 / 403)$ of the seasonal workers did not know whether they used any measures that are protective against the bite of sand flies and the acquisition of kala azar. Only $11.7 \%$ (47/403) reported sleeping under an ITN. The vast majority of the workers who did not use an ITN reported that it was because they had no access to one (93.3\%, 332/356). All the workers who reported that they used an ITN did so during the early rainy season (June-July). In all, $14.1 \%(57 / 403)$ of the interviewed seasonal workers reported using local methods to protect themselves from sand fly bites, and the commonest local method reported by the workers was smoke $(92.4 \%, 49 / 53)$. One-third $(34.5 \%, 139 / 403)$ of the seasonal workers reported that they consistently used long sleeves/trousers/socks to protect themselves from sand fly bites, and $13.4 \%$ (54/403) used commercial repellents (Table 5).

Frequency of practices that predispose the seasonal/ migrant workers to sand fly bites. Nearly two-thirds $(63 \%$, 254/403) of the interviewed seasonal/migrant workers reported that during the harvesting season, they always work in the evening or night; their most common reason for evening or night work was cooler temperatures (62.5\%, 168/269). Fewer than half $(45.4 \%, 182 / 403)$ of the workers had access to shelters for night sleeping. The remainder slept either on open farmlands $(32.0 \%, 129 / 403)$ or under the shade of trees $(22.6 \%, 91 / 403)$. Only $2.3 \%$ of the workers $(9 / 400)$ reported having a bed for sleeping; the great majority $(78.2 \%, 313 / 400)$ used plastic sheeting ("sleep-mats") on the floor or just slept

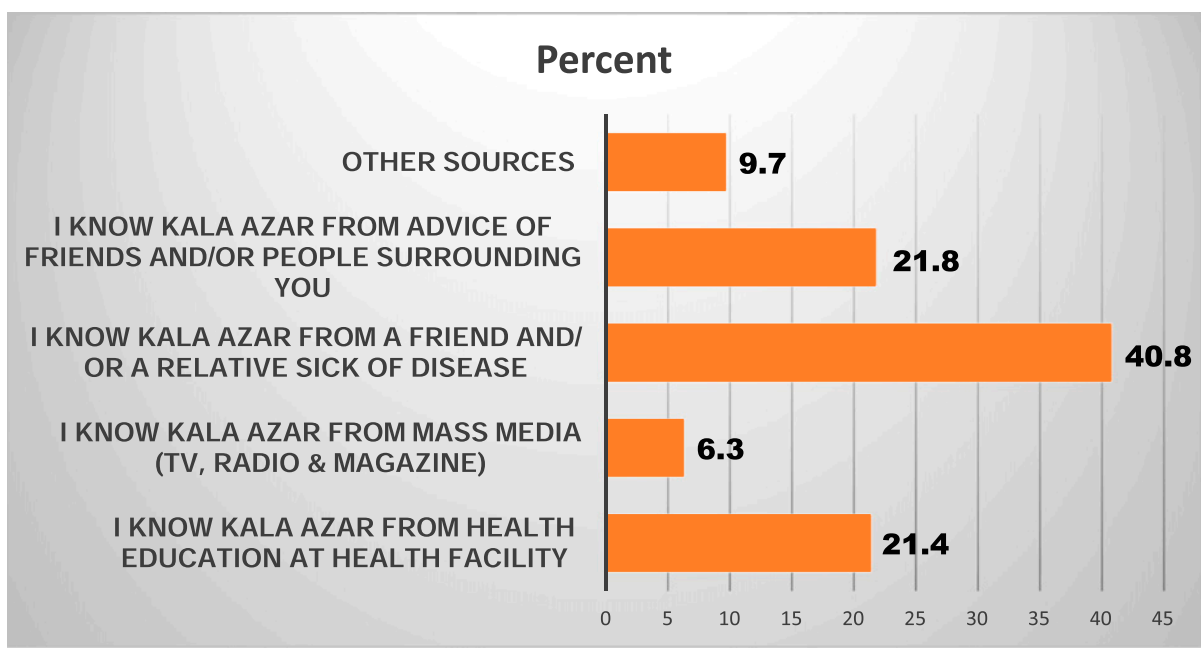

FIGURE 1. Reported source of information among seasonal and migrant workers with any exposure to health education messages on kala azar disease and sand fly bites in the lowland agricultural farms of the Amhara region. This figure appears in color at www.ajtmh.org. 
TABLE 3

Responses of seasonal/migrant workers in agricultural farms in northwest Ethiopia to questions on their knowledge of kala azar disease, 2017

\begin{tabular}{lrr}
\hline \multicolumn{1}{c}{ Variable } & Frequency & $\%$ \\
\hline Signs and symptoms of kala azar & & \\
mentioned by workers & & \\
$\quad$ Extended fever & 50 & 12.4 \\
Splenomegaly & 41 & 10.2 \\
Weight loss & 25 & 6.2 \\
$\quad$ Nose bleeding & 38 & 9.4 \\
$\quad$ Extended fever, splenomegaly, and & 74 & 18.4 \\
$\quad$ weight loss & & \\
Consequence of kala azar mentioned by & & \\
workers & 168 & 41.7 \\
$\quad$ Death & 174 & 43.2 \\
$\quad$ Pain and discomfort & 64 & 15.9 \\
$\quad$ Loss of income & & \\
Kala azar-endemic areas as reported by & & \\
seasonal workers & 185 & 45.9 \\
$\quad$ Lowland & 6 & 1.5 \\
$\quad$ Highland & 45 & 11.2 \\
$\quad$ Do not know & & \\
Transmission of kala azar mentioned by & & \\
seasonal workers & 71 & 17.6 \\
$\quad$ Polluted water & 7.7 \\
$\quad$ Sexual intercourse & 102 & 25.5 \\
$\quad$ Insect bite & 21 & 5.2 \\
$\quad$ Contaminated food & 33 & 8.2 \\
$\quad$ Do not know & & \\
\hline
\end{tabular}

on the bare ground without any material $(18.0 \%, 72 / 400)$ (Table 6).

Willingness to pay for measures that can protect from sand fly bites. Figure 3 presents responses of the seasonal/ migrant workers to questions on their WTP for control measures that can protect them against sand fly bites. A total of $315(78.2 \%)$ seasonal/migrant workers were willing to pay some amount for one or more protective measures. Among those willing to pay, half $(49.8 \%, 157 / 315)$ responded that they could pay a maximum of 50 Ethiopian birr per season (1.9 USD), whereas the other half $(50.2 \%, 158 / 315)$ of the workers expressed their WTP more than 50 Ethiopian birr (1.9 USD) for protective measures. Based on price and expected protection, the workers were most likely to be willing to pay for an ITN (40.3\%, 159/395), followed by local neem oil $(29.6 \%, 117 /$ 395), a long-lasting commercial tropical repellent $(27.1 \%, 107 /$ $395)$, and permethrin-impregnated socks $(21.0 \%, 83 / 395)$ (Figure 3).

Factors associated with knowledge of seasonal/migrant workers of kala azar and its vector control. Logistic regression results of potential socioeconomic and demographic factors that could influence the knowledge of seasonal/ migrant workers on kala azar are presented in Supplemental Table 3.

In the bivariate analysis, educational status, frequency of visiting this area, health education, and average daily income were significantly associated with the knowledge of seasonal/ migrant workers on kala azar disease and its vector (Supplemental Table 3).

A multivariable analysis was used to identify factors that are significantly associated with the knowledge of the workers on kala azar disease and its vectors, when all variables are considered together. Of six variables included in the analysis, only educational status and previous health education on kala azar
TABLE 4

Responses of seasonal/migrant workers in agricultural farms in northwest Ethiopia to questions on their knowledge of sand flies, 2017

\begin{tabular}{|c|c|c|}
\hline Variable & Frequency & $\%$ \\
\hline \multicolumn{3}{|l|}{ How seasonal workers described sand fly } \\
\hline Larger than mosquito & 41 & 10.2 \\
\hline Same size as mosquito & 34 & 8.4 \\
\hline Smaller than mosquito & 47 & 11.7 \\
\hline Insect has two vertical wings & 4 & 1.0 \\
\hline Dark color insect & 13 & 3.2 \\
\hline Light or yellowish color insect & 13 & 3.2 \\
\hline Do not know & 244 & 60.5 \\
\hline \multicolumn{3}{|l|}{$\begin{array}{l}\text { Workers correctly knew the picture of } \\
\text { sand fly }(N=367)\end{array}$} \\
\hline Yes & 36 & 9.8 \\
\hline No & 331 & 90.2 \\
\hline \multicolumn{3}{|l|}{$\begin{array}{l}\text { Time of sand fly bite reported by seasonal } \\
\text { workers }^{\star}\end{array}$} \\
\hline During daytime & 13 & 3.2 \\
\hline During evening time & 193 & 47.9 \\
\hline During nighttime & 177 & 43.9 \\
\hline Do not know & 185 & 45.9 \\
\hline \multicolumn{3}{|l|}{$\begin{array}{l}\text { Reported places where sand fly bites } \\
\text { seasonal workers }{ }^{\star}\end{array}$} \\
\hline Near acacia tree & 143 & 35.5 \\
\hline Near Balanites tree & 110 & 27.3 \\
\hline Near Combertium tree & 20 & 5.0 \\
\hline Near open grass cover tree & 72 & 17.9 \\
\hline Black cotton soil & 129 & 32.0 \\
\hline Near water & 42 & 10.4 \\
\hline Do not know & 185 & 45.9 \\
\hline \multicolumn{3}{|l|}{$\begin{array}{l}\text { Reported seasons when sand fly bites } \\
\text { seasonal workers* }\end{array}$} \\
\hline Early rainy season (June-July) & 216 & 53.6 \\
\hline Late rainy season (August-Sept) & 179 & 44.4 \\
\hline Early dry season (October-February) & 38 & 9.4 \\
\hline Late dry season (March-May) & 21 & 5.2 \\
\hline Do not know & 168 & 41.7 \\
\hline
\end{tabular}

disease were independently associated with the knowledge of the workers (Table 7).

Seasonal workers with any formal education were twice as likely to have a moderate/high level of knowledge of kala azar than those who did not have any formal education (AOR = $2.11,95 \% \mathrm{Cl}=[1.17,3.80], P<0.05)$. Similarly, seasonal workers who had attended health education on kala azar were almost 5 times more likely to have moderate/high-level of knowledge of kala azar than their counterparts who did not receive any health education messages $(\mathrm{AOR}=4.72,95 \% \mathrm{Cl}=$ [1.99, 11.16], $P<0.001)$.

Factors associated with practice of measures that protect against sand fly bites. In the bivariate analysis, educational status, frequency of visiting the area, number of weeks in the area, and health education on kala azar were found to have a $P$-value $<0.2$ (Supplemental Table 4).

Although educational status, frequency of visiting the farm areas, duration of presence in the farm areas, health education, and average daily salary were selected for the multivariable binary logistic regression, only previous exposure to kala azar health education messages showed significant association with fair/good preventive practice of seasonal workers (Table 8). Seasonal workers who attended health education on kala azar before this cross-sectional study had 5.47 times higher odds of reporting fair/good practice than those who had not experienced any health education (AOR $=5.47,95 \%$ $\mathrm{Cl}=[1.30,23.02])$. 


\section{Percent}

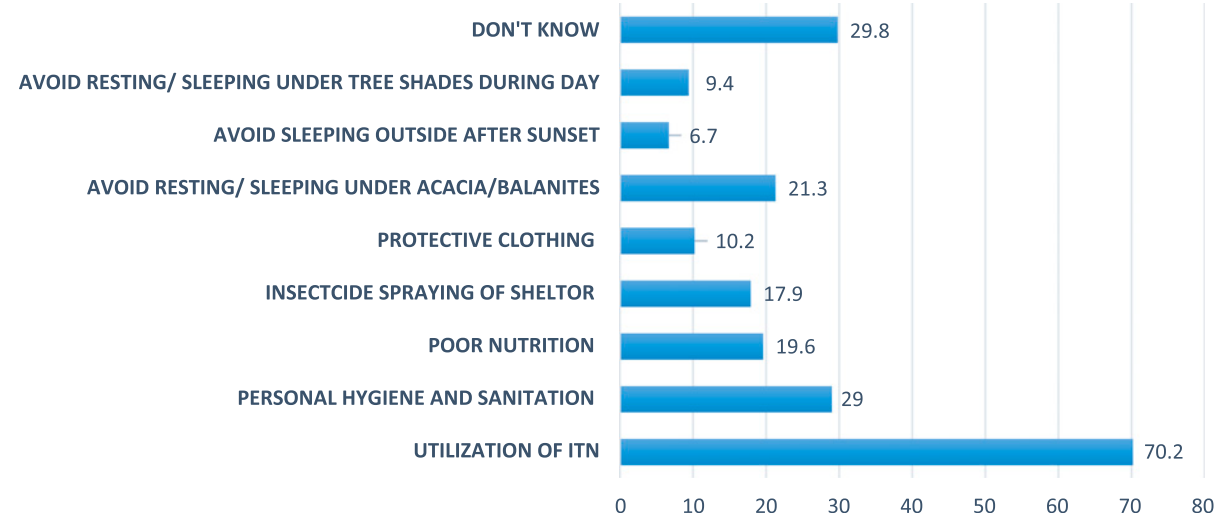

FIGURE 2. Responses of seasonal or migrant workers in lowland agricultural farms in Abdurafi and Metema areas of northwest Ethiopia to questions on their knowledge of possible sand fly bite prevention measures, 2017. This figure appears in color at www.ajtmh.org.

\section{DISCUSSION}

This study focused on determining the knowledge and practice of seasonal/migrant workers in lowlands of northwest Ethiopia in relation to sand fly bite exposure and WTP for sand fly control measures. Based on a combined score across 12 core knowledge questions, $61.8 \%, 24.6 \%$, and $13.6 \%$ of seasonal workers had poor, moderate, and good levels of knowledge on kala azar and its vector, respectively. The level of poor knowledge reported by this study is greater than that of a study conducted in Morang resident communities, Nepal. ${ }^{15}$ Similarly, the proportion of knowledgeable respondents of this study is lower than the result of a study in residents of Addis Zemen, Ethiopia (89.4\%). ${ }^{11}$ Based on a combined score across 9 core preventive practice questions, $95.0 \%$ of the seasonal workers had poor practice against prevention of kala azar disease and sand fly bites. Very few, (3.5\%) and (1.5\%), workers had fair and good-level practice, respectively. The proportion of workers with fair or good-level practice reported by this study is much lower than the proportion reported by the studies in Morang resident communities, Nepal (78\%), ${ }^{15}$ and Addis Zemen, Ethiopia (68.6\%). ${ }^{11}$ Fifty-nine percent of the participants of this study reported attending any formal education, which is lower than the reports of studies in Morang, Nepal (89\%), ${ }^{15}$ and Addis Zemen (66\%) ${ }^{11}$ resident communities. This is not meant to be a strict comparison, however, as participants in this study were seasonal/migrant workers, and there might also be additional differences in the knowledge and practice questions and indices used.

Seventy-eight percent of the seasonal workers were willing to pay for different sand fly bite protective measures, which is a slightly lower proportion than the result of a similar study in Brazil (86.4\%). ${ }^{16}$ This might be because of income difference. The study participants from Brazil get more income than the study participants in the current study.

In this study, only one-tenth of the study participants reported that splenomegaly is a sign of kala azar disease. Although the proportion varies, $18.8 \%$ of study participants in Addis Zemen, Ethiopia, ${ }^{11}$ and $51 \%$ of study participants in Kenya ${ }^{17}$ described that splenomegaly is a chief sign of kala azar. In this study, $41.7 \%$ of the respondents knew that if the disease is left untreated, the outcome will be death. The proportion of respondents who mentioned death as a consequence of kala azar is lower than the proportion reported by a study in Addis Zemen (96.7\%). ${ }^{11}$ Sixteen percent of our study participants believed that kala azar could affect their income. Similarly, all (100\%) study participants of another study reported that this disease could affect their income. ${ }^{18}$ Twenty-nine percent of our study participants correctly knew the vector of kala azar disease, which is greater than the proportion reported by a study in India $(4.3 \%),{ }^{18}$ in Morang, Nepal (18.7\%), ${ }^{15}$ in Sudan (6\%), ${ }^{19}$ and in Bihar $(0.9 \%) .{ }^{20}$ However, this result is lower than the result of another study in Addis Zemen (68.1\%). ${ }^{11}$ This study reported that $56.4 \%$ of workers did not know the correct transmission mode of kala azar disease, which is by far greater than the proportion reported by another study (26\%). ${ }^{18}$ In the current study, $8.2 \%$ workers believed that kala azar disease is transmitted by mosquito bites, which is much lower than the report of other studies $(62.8 \%),{ }^{18}$ and the proportion of workers who knew sand fly is much less than the proportion reported by a study in India $(76 \%)^{18}$

In this study, $43.9 \%$ of study subjects reported that sand fly bites in the night, which is consistent with the report of a study in Bihar $(40 \%) .{ }^{21}$ One-tenth $(10.4 \%)$ of participants of the current study said that sand fly breeds in polluted water. Similarly, a higher proportion of participants of studies in Bahir $(63.6 \%)^{21}$ and Morang, Nepal $(59.3 \%),{ }^{15}$ reported polluted water as a breeding site. Regarding the season when sand fly actively bites, participants of this study said that sand fly actively bites during the early rainy season (53.6\%), late rainy season $(44.4 \%)$, early dry season $(9.4 \%)$, and late dry season $(5.2 \%)$, which is inconsistent with the report of a study in Kenya. Participants of a study in Kenya reported that sand fly actively bites in the very hot and dry season (22.3\%), beginning of the rainy season $(11.7 \%)$, and cold and rainy season $(11.4 \%) .^{18}$

This study depicted that a significant proportion (41\%) of study participants did not know the prevention measures of kala azar and sand fly bites. A study conducted in India reported that $66 \%$ did not know about the prevention measures. ${ }^{18}$ This study also showed that $70 \%$ of the study subjects believed that mosquito bed nets could prevent sand fly bites, which is much greater than the proportion reported by studies in India (19.7\%) ${ }^{18}$ and Morang, Nepal $(64.8 \%),{ }^{15}$ and 
TABLE 5

Responses of seasonal migrant workers in agricultural farms of Abdurafi and Metema areas (northwest Ethiopia) to questions on methods they use to protect themselves from sand fly bites and kala azar (June-October 2017)

\begin{tabular}{|c|c|c|}
\hline Variable & Frequency & $\%$ \\
\hline \multicolumn{3}{|l|}{$\begin{array}{l}\text { Reported measures used for protection from } \\
\text { bites of sand fly }(N=403)^{\star}\end{array}$} \\
\hline Sleeping under ITNs & 47 & 11.7 \\
\hline Keeping personal hygiene and sanitation & 102 & 25.3 \\
\hline Proper nutrition & 72 & 17.9 \\
\hline $\begin{array}{l}\text { Insecticide spraying in the shelters or } \\
\text { surrounding environment }\end{array}$ & 46 & 11.4 \\
\hline Protective clothing & 27 & 6.7 \\
\hline $\begin{array}{l}\text { Avoiding resting/sleeping under acacia/ } \\
\text { Balanites trees }\end{array}$ & 5 & 1.2 \\
\hline $\begin{array}{l}\text { Avoiding staying/sleeping outside } \\
\text { shelters and huts after sunset }\end{array}$ & 24 & 6.0 \\
\hline $\begin{array}{l}\text { Avoiding resting/sleeping under tree } \\
\text { shade during the day }\end{array}$ & 33 & 8.2 \\
\hline Nothing & 172 & 42.7 \\
\hline \multicolumn{3}{|l|}{ ITN use at different seasons $(N=47)$} \\
\hline During early rainy season (June-July) & 47 & 100.0 \\
\hline $\begin{array}{l}\text { During late rainy season } \\
\text { (August-September) }\end{array}$ & 32 & 68.1 \\
\hline $\begin{array}{l}\text { During early dry season } \\
\text { (October-February) }\end{array}$ & 4 & 8.5 \\
\hline During late dry season (March-May) & 2 & 4.3 \\
\hline \multicolumn{3}{|l|}{ Reasons for not using ITN $(N=356)$} \\
\hline Not available & 332 & 93.3 \\
\hline Not effective & 2 & 0.6 \\
\hline Uncomfortable & 4 & 1.1 \\
\hline Difficult to install & 15 & 4.2 \\
\hline Others & 8 & 2.2 \\
\hline \multicolumn{3}{|l|}{$\begin{array}{l}\text { Do you use local methods to protect against } \\
\text { sand fly bite? }\end{array}$} \\
\hline Yes & 53 & 13.2 \\
\hline No & 350 & 86.4 \\
\hline \multicolumn{3}{|l|}{ Locally practiced methods $(N=53)$} \\
\hline Smoke & 49 & 92.4 \\
\hline Local repellent (smoking) & 2 & 3.8 \\
\hline Others & 2 & 3.8 \\
\hline \multicolumn{3}{|l|}{$\begin{array}{l}\text { Consistent use of protective clothing (long } \\
\text { sleeves shirts, trousers, and socks) }\end{array}$} \\
\hline Yes & 139 & 34.5 \\
\hline No & 264 & 65.5 \\
\hline \multicolumn{3}{|l|}{$\begin{array}{l}\text { Reasons for lack of consistent use of } \\
\text { protective clothes against sand fly }(N=264)\end{array}$} \\
\hline Not aware of effectiveness & 148 & 56.2 \\
\hline Uncomfortable to use & 25 & 9.5 \\
\hline Too expensive & 8 & 3.0 \\
\hline Do not know & 63 & 24 \\
\hline Others & 6 & 2.3 \\
\hline \multicolumn{3}{|l|}{ Seasons of wearing protective clothes } \\
\hline During early rainy season (June-July) & 282 & 70.0 \\
\hline $\begin{array}{l}\text { During late rainy season } \\
\text { (August-September) }\end{array}$ & 177 & 43.9 \\
\hline $\begin{array}{l}\text { During early dry season } \\
\text { (October-February) }\end{array}$ & 27 & 6.7 \\
\hline During late dry season (March-May) & 18 & 4.5 \\
\hline During all the seasons & 24 & 6.0 \\
\hline \multicolumn{3}{|l|}{ Use commercial repellents? } \\
\hline Yes & 54 & 13.4 \\
\hline No & 348 & 86.4 \\
\hline \multicolumn{3}{|l|}{$\begin{array}{l}\text { Reasons for not using commercial repellents } \\
(N=348)\end{array}$} \\
\hline Not aware of them & 284 & 81.6 \\
\hline Not available & 19 & 5.5 \\
\hline Too expensive & 25 & 7.2 \\
\hline Do not like to put anything on my skin & 4 & 1.1 \\
\hline Others & 8 & 2.3 \\
\hline
\end{tabular}

* Multiple responses.
TABLE 6

Responses of seasonal/migrant workers in Abdurafi-Metema lowland agricultural farms of northwest Ethiopia to questions on factors that predispose them to sand fly bites (June-October 2017)

\begin{tabular}{|c|c|c|}
\hline Variable & Frequency & $\%$ \\
\hline \multicolumn{3}{|l|}{$\begin{array}{l}\text { Do you work in the evening/night? } \\
(N=402)\end{array}$} \\
\hline Yes, always (harvest) & 254 & 63. \\
\hline Yes, sometimes & 75 & 18. \\
\hline No & 73 & 18. \\
\hline \multicolumn{3}{|l|}{$\begin{array}{l}\text { Reasons for working at night/evening } \\
\qquad(N=269)\end{array}$} \\
\hline Asked to work by farm owners & 23 & 8 \\
\hline To make more money & 37 & 13 \\
\hline Cooler than daytime & 168 & 62 \\
\hline Others & 41 & 15 \\
\hline \multicolumn{3}{|l|}{$\begin{array}{l}\text { If you sometimes work by night, which } \\
\text { activities do you do? }(N=75)^{\star} \dagger\end{array}$} \\
\hline During farm preparation & 6 & \\
\hline During harvesting & 75 & 100 \\
\hline During weeding (cooking their food) & 35 & 46. \\
\hline \multicolumn{3}{|l|}{$\begin{array}{l}\text { Availability of houses and shelters for } \\
\text { sleeping during day or night }\end{array}$} \\
\hline Yes & 182 & 45 \\
\hline No & 219 & 54 \\
\hline \multicolumn{3}{|l|}{$\begin{array}{l}\text { Types of house provided by the farm } \\
\text { owner }(N=182)\end{array}$} \\
\hline Shelter & 81 & 44 \\
\hline Sub-shelter & 70 & 38 \\
\hline Normal hut & 31 & 17 \\
\hline \multicolumn{3}{|l|}{$\begin{array}{l}\text { Are shelters/shades sprayed with } \\
\text { insecticide }(N=333)\end{array}$} \\
\hline Yes & 16 & \\
\hline No & 225 & 55 \\
\hline Do not know & 92 & 22 \\
\hline \multicolumn{3}{|l|}{$\begin{array}{l}\text { When was the last time shelters/shades } \\
\text { sprayed with insecticides? }(N=16)\end{array}$} \\
\hline Less than 6 months & 9 & 56. \\
\hline $6-12$ months & 4 & 25. \\
\hline Do not know & 3 & \\
\hline \multicolumn{3}{|l|}{ Sleeping near animals in the farm $(N=328)$} \\
\hline Yes & 31 & \\
\hline No & 297 & 90 \\
\hline
\end{tabular}

Places of sleep when houses or shelters are not provided $(N=221)$

Under dense tree

Under sparse tree

Open farmland

Others

8.0

46.7

5.4

4.6

44.5

38.5

17.0

4.0

55.8

22.8

56.3

25.0

18.8

9.5
90.5

If you do not have a bed, where did you

sleep? $(N=400)$

Bedding structure raised off the $\quad 9 \quad 2.3$ ground

$\begin{array}{lll}\text { Just on the ground without any } & 72 & 18.0\end{array}$

material underneath

Sleeping on a plastic sheet $\quad 313 \quad 78.3$

$\begin{array}{lrr}\text { Others } & 3 & 0.8\end{array}$

* The percentage was calculated based on respondents who sometimes work at night. † Multiple responses are possible.

less than the proportion reported by a study in Bihar (92.8\%). ${ }^{21}$ Moreover, the current study explored that $17.9 \%$ of workers knew that insecticide spraying could prevent sand flies, which is in line with the report of a study in India $(17.1 \%)^{18}$ and much less than the report of a study in Morang, Nepal $(61.5 \%) .^{15}$

As investigated by this study, $11.7 \%$ of study participants prevent themselves by ITN utilization. The proportion of study subjects who used ITN is much lower than the proportions reported by studies in Morang, Nepal (89\%), ${ }^{15}$ Addis Zemen (19.8\%), ${ }^{11}$ and Bihar (20\%). ${ }^{20}$ The current study also reported that $11.4 \%$ of study subjects used chemical spraying as a 


\section{Percent}

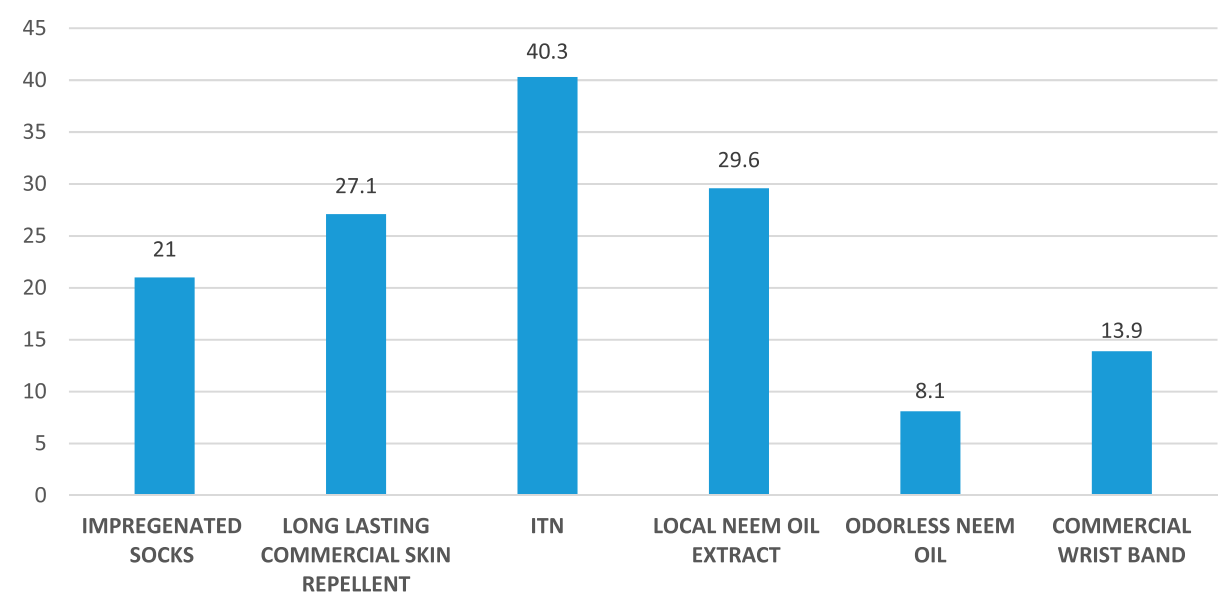

FIGURE 3. Percentages of 403 seasonal/migrant agricultural workers in Abdurafi-Metema farms (northwest Ethiopia) who responded that they are willing to pay for different sand fly protective measures (June-October 2017). This figure appears in color at www.ajtmh.org.

protective measure, which is lower than the reports of the previous studies.

This study investigated the predisposing factors for sand fly bites. Working in the evening or night (63\%), sleep outdoor (54.6\%), not spraying sheds/shelters (55.8\%), sleeping near barns $(7.7 \%)$, sleep under tree sheds $(41.2 \%)$, and poor ITN utilization $(11.7 \%)$ were some of the predisposing factors. Similarly, in the study performed on residents and migrant workers in Kafta-Humera, Ethiopia, sleeping under an acacia tree at night, indicators of poverty, lower educational status, and sleeping dogs were found to be associated with increased risk of kala azar. ${ }^{13}$ Therefore, this study gives additional evidence on the predisposing factors for sand fly bites, and this will help to target these factors for intervention.

This cross-sectional study identified that formal education and exposure to health education on kala azar were statistically significant predictors of moderate/high-level knowledge on kala azar among seasonal workers in this area of Ethiopia.
Moreover, exposure to health education on kala azar was a statistically significant predictor of fair/good preventive practice of seasonal workers against kala azar diseases and sand fly bites; however, it is important to note that the $\mathrm{Cl}$ around this adjusted OR is wide because of the very small number of respondents who report fair/good practice (20/ 403). These findings are consistent with other studies. ${ }^{22-24}$ This might be because of the fact that health education promotes awareness about the transmission and prevention methods of infectious diseases. Education encourages changes in preventive behaviors and practice. ${ }^{23,25-27}$

The findings of this study should be interpreted with some limitations. The study relies on male participants, who were the majority. The reason for not including females is because we could not manage to get access to female seasonal/ migrant workers working on the farms. Although we have made efforts to select 8 farms by using a purposive sampling technique, selection bias might be the inherent limitation of

TABLE 7

Multivariable analysis of factors associated with knowledge of seasonal workers $(n=403)$ on kala azar diseases and sand fly bite in lowlands of northwest Ethiopia (June-November 2017)

\begin{tabular}{|c|c|c|c|c|}
\hline \multirow[b]{2}{*}{ Variable } & \multicolumn{2}{|c|}{ Level of knowledge } & \multirow[b]{2}{*}{ Crude odds ratio, $95 \% \mathrm{Cl}$} & \multirow[b]{2}{*}{ Adjusted odds ratio, $95 \% \mathrm{C}$} \\
\hline & Moderate/high & Low & & \\
\hline \multicolumn{5}{|l|}{ Age of participants (years) } \\
\hline$\leq 30$ & 125 & 216 & 1 & 1 \\
\hline$>30$ & 29 & 33 & $1.52(0.88,2.62)$ & $2.06(0.91,4.67)$ \\
\hline \multicolumn{5}{|l|}{ Educational status } \\
\hline No formal education & 47 & 116 & 1 & 1 \\
\hline Formal education & 107 & 129 & $2.05(1.34,3.13)$ & $2.11(1.17,3.80) \dagger$ \\
\hline \multicolumn{5}{|c|}{ Frequency of visiting this area } \\
\hline $1-4$ times & 97 & 190 & 1 & 1 \\
\hline More than 4 times & 55 & 59 & $1.83(1.17,2.84)$ & $1.65(0.91,3.00)$ \\
\hline \multicolumn{5}{|l|}{ Weeks stayed in this area } \\
\hline For at least 3 weeks & 88 & 163 & 1 & 1 \\
\hline More than 3 weeks & 65 & 86 & $1.40(0.93,2.12)$ & $1.69(0.95,3.00)$ \\
\hline \multicolumn{5}{|c|}{$\begin{array}{l}\text { Attending health education on VL } \\
\text { delivered every year during weeding } \\
\text { and harvesting seasons }\end{array}$} \\
\hline Yes & 44 & 7 & $5.25(2.26,12.21)$ & $4.72(1.99,11.16) \ddagger$ \\
\hline No & 109 & 91 & 1 & 1 \\
\hline
\end{tabular}

† Statistically significant at $P<0.05$.

$\neq$ Statistically significant at $P<0.001 \mid$ Hosmer and Lemeshow test $=0.691,1=$ reference. 
TABLE 8

Multivariable analysis of factors associated with fair/good practice of sand fly bite and kala azar protective measures among seasonal/migrant workers in lowland agricultural farms of Abdurafi and Metemma areas of northwest Ethiopia $(n=403)$ from June to November 2017

\begin{tabular}{|c|c|c|c|c|}
\hline \multirow[b]{2}{*}{ Variable } & \multicolumn{2}{|c|}{ Level of practice } & \multirow[b]{2}{*}{ Crude odds ratio, $95 \% \mathrm{Cl}$} & \multirow[b]{2}{*}{ Adjusted odds ratio, $95 \% \mathrm{Cl}$} \\
\hline & Fair/good practice ${ }^{\star}$ & Poor practice & & \\
\hline \multicolumn{5}{|l|}{ Educational status } \\
\hline No formal education & 5 & 158 & 1 & 1 \\
\hline Formal education & 15 & 221 & $2.15(0.76,6.02)$ & $5.14(0.61,43.37)$ \\
\hline \multicolumn{5}{|c|}{ Frequency of visiting the area } \\
\hline $1-4$ times & 11 & 276 & 1 & 1 \\
\hline More than 4 times & 8 & 106 & $1.89(0.74,4.84)$ & $0.89(0.22,3.68)$ \\
\hline \multicolumn{5}{|c|}{ Number of weeks in the area } \\
\hline At least 3 weeks & 8 & 243 & 1 & 1 \\
\hline More than 3 weeks & 11 & 140 & $2.39(0.94,6.07)$ & $3.13(0.79,12.39)$ \\
\hline \multicolumn{5}{|c|}{$\begin{array}{l}\text { Attending health education on visceral } \\
\text { leishmaniasis delivered every year } \\
\text { during weeding and harvesting } \\
\text { seasons }\end{array}$} \\
\hline Yes & 5 & 46 & $3.51(1.03,12.02)$ & $5.47(1.30,23.02) \dagger$ \\
\hline No & 6 & 194 & 1 & 1 \\
\hline \multicolumn{5}{|c|}{ Average daily salary (Ethiopian birr) } \\
\hline$<100$ & 11 & 181 & 1 & 1 \\
\hline $100-150$ & 3 & 119 & $0.42(0.11,1.52)$ & $0.44(0.05,4.05)$ \\
\hline$>150$ & 6 & 83 & $1.19(0.43,3.33)$ & $4.26(0.87,20.87)$ \\
\hline
\end{tabular}

† Statistically significant at $P<0.05 \mid$ Hosmer and Lemeshow test $=0.499,1=$ reference.

this study. Administration of the questionnaire during the faceto-face interview might have resulted in a social desirability bias, no matter how much confidentiality was maintained throughout the process.

\section{CONCLUSION AND RECOMMENDATIONS}

Overall, a wide range of knowledge and practice gap was seen among seasonal workers about kala azar disease and its vector. A high proportion of the workers had poor knowledge and practice level on kala azar disease and sand fly bite prevention. The vast majority of the workers misunderstood the transmission mode of kala azar disease. Most of the workers did not know the vector of kala azar disease. The overwhelming majority did not differentiate sand fly from other mosquitoes. Almost all of the workers were vulnerable to kala azar disease or sand fly bites. Most workers did not use any single effective measure to protect themselves from sand fly bites. But the good thing is more than three-quarters were willing to buy and use protective measures if the measures could be available in the local market. Educational status and health education were the identified factors associated with good levels of knowledge and practice. Therefore, providing well-organized and regular health education for the workers is recommended to improve workers' knowledge and practice. Moreover, workers should have access to affordable protective measures in the local market. Selling sand fly protective measures in the already existing local markets with low prices increases the utilization of personal protective measures.

Received April 22, 2019. Accepted for publication October 26, 2019. Published online February 10, 2020.

Note: Supplemental tables appear at www.ajtmh.org.

Acknowledgments: We forward our appreciation to the farm owners and managers of all study sites for allowing us to conduct this research. Our special appreciation goes to the study participants for their volunteer participation. Finally, we thank district health office heads for their support throughout the process.
Financial support: The study was funded by DfiD, UKAID.

Disclosure: The datasets supporting the conclusions of this article are available upon request to the corresponding author. Due to data protection restrictions and participant confidentiality, we do not make participants data publicly available.

Authors' addresses: Mekuriaw Alemayehu and Zemichael Gizaw, Department of Environmental Health and Safety, Institute of Public Health, College of Medicine and Health Sciences, University of Gondar, Gondar, Ethiopia, E-mails: mekuriaw14@gmail.com and zemicheal12@gmail.com. Lucy Paintain, Department of Disease Control, Faculty of Infectious and Tropical Diseases, London School of Hygiene \& Tropical Medicine, London, United Kingdom, E-mail: lucy.paintain@Ishtm.ac.uk. Cherinet Adera, KalaCORE Country Office, Addis Ababa, Ethiopia, E-mail: cherinetadera@yahoo.com. Resome Berhe and Adane Nigusie, Department of Health Education and Behavioral Sciences, Institute of Public Health, College of Medicine and Health Sciences, University of Gondar, Gondar, Ethiopia, E-mails: resom.berhe86@gmail.com and adane_n@yahoo.com. Abebaw Gebeyehu, Department of Reproductive Health, Institute of Public Health, College of Medicine and Health Sciences, University of Gondar, Gondar, Ethiopia, E-mail: herreromerce@gmail.com. Merce Herrero, KalaCORE, London, United Kingdom, E-mail: zemicheal12@gmail.com. Abate Mulugeta Beshah, WHO Country Office, Addis Ababa, Ethiopia, E-mail: abatem@who.int. Margriet Den Boer, KalaCORE Coordinator for East Africa, London, United Kingdom, E-mail: margrietdenboer@ gmail.com. Meseret Alem, Department of Immunology and Molecular Biology, School of Biomedical and Laboratory Science, University of Gondar, Gondar, Ethiopia, E-mail: mesey4839@gmail.com. Enyew yechale, KalaCORE Regional Office, Bahir Dar, Ethiopia, E-mail: enyard00@gmail.com. Dia-Eldin A. Elnaiem, Department of Natural Sciences, University of Maryland Eastern Shore, Princess Anne, MD, E-mail: dialnaiem@gmail.com.

\section{REFERENCES}

1. Alvar J, Velez ID, Bern C, Herrero M, Desjeux P, Cano J, Jannin J, den Boer M; WHO Leishmaniasis Control Team, 2012. Leishmaniasis worldwide and global estimates of its incidence. PLoS One 7: e35671.

2. Hailu A, Gramiccia M, Kager P, 2009. Visceral leishmaniasis in Aba-Roba, south-western Ethiopia: prevalence and incidence of active and subclinical infections. Ann Trop Med Parasitol 103: 659-670. 
3. Tsegaw T, Gadisa E, Seid A, Abera A, Teshome A, Mulugeta A, Herrero M, Argaw D, Jorge A, Aseffa A, 2013. Identification of environmental parameters and risk mapping of visceral leishmaniasis in Ethiopia by using geographical information systems and a statistical approach Geospat Health 7: 299-308.

4. Berhane $\mathrm{Y}$, Mariam DH, Kloos $\mathrm{H}, 2006$. Epidemiology and Ecology of Health and Disease in Ethiopia. Addis Ababa, Ethiopia: Shama books.

5. ANON, 2007. Tigray Regional Report: Livelihood Profile Tigray Region, Ethiopia. Humera Sesame and Sorghum Livelihood Zone. Mekelle, Ethiopia: Tigray Regional Health Office.

6. Lemma W, Tekie H, Yared S, Balkew M, Gebre-Michael T, Warburg A, Hailu A, 2015. Sero-prevalence of Leishmania donovani infection in labour migrants and entomological risk factors in extra-domestic habitats of Kafta-Humera lowlandskala-azar endemic areas in the northwest Ethiopia. BMC Infect Dis 15: 99.

7. Reithinger R, Brooker S, Kolaczinski H, 2007. Visceral leishmaniasis in eastern Africa-current status. Trans $R$ Soc Trop Med Hyg 101: 1169-1170.

8. Yared S, Deribe K, Gebreselassie A, Lemma W, Akililu E, Kirstein OD, Balkew M, Warburg A, Gebre-Michael T, Hailu A, 2014. Risk factors of visceral leishmaniasis: a case control study in north-western Ethiopia. Parasit Vectors 7: 470

9. Leta S, Dao THT, Mesele F, Alemayehu G, 2014. Visceral leishmaniasis in Ethiopia: an evolving disease. PLoS Negl Trop Dis 8: e3131.

10. Alvar J et al., 2007. Kala-azar outbreak in Libo Kemkem, Ethiopia: epidemiologic and parasitologic assessment. Am J Trop Med Hyg 77: 275-282.

11. Alemu A, Alemu A, Esmael N, Dessie Y, Hamdu K, Mathewos B, Birhan W, 2013. Knowledge, attitude and practices related to visceral leishmaniasis among residents in Addis Zemen town, South Gondar, Northwest Ethiopia. BMC Public Health 13: 382.

12. López-Perea N, Sordo L, Gadisa E, Cruz I, Hailu T, Moreno J, Aseffa A, Cañavate C, Custodio E, 2014. Knowledge, attitudes and practices related to visceral leishmaniasis in rural communities of Amhara state: a longitudinal study in northwest Ethiopia. PLoS Negl Trop Dis 8: e2799.

13. Argaw D, Mulugeta A, Herrero M, Nombela N, Teklu T, Tefera T, Belew Z, Alvar J, Bern C, 2013. Risk factors for visceral leishmaniasis among residents and migrants in Kafta-Humera, Ethiopia. PLoS Negl Trop Dis 7: e2543.

14. Bloom BS 1956. Taxonomy of Educational Objectives: Handbook I. Cognitive Domain. New York, NY: David McKay.

15. Bista S, Sapkota S, Akela G, 2017. Knowledge and practice regarding kala azar among community people of Dangihat, Morang. J Chitwan Med Coll 7: 43-49.
16. Esch K, Pontes N, Arruda P, O'Connor A, Morais L, Jeronimo SM, Petersen CA, 2012. Preventing zoonotic canine leishmaniasis in northeastern Brazil: pet attachment and adoption of community leishmania prevention. Am J Trop Med Hyg 87: 822-831.

17. Lotukoi J, Anjili C, Kutima H, Wanzala P, 2017. Knowledge, attitude, perception and the behaviour of the community towards visceral leishmaniasis (kala azar) in Loima sub-county of Turkana county, Kenya. Indian J Med Res Pharm Sci 4: 29-47.

18. Siddiqui N, Kumar N, Ranjan A, Pandey K, Das VN, Verma RB, Das $P, 2010$. Awareness about kala-azar disease and related preventive attitudes and practices in a highly endemic rural area of India. Southeast Asian J Trop Med Public Health 41: 1.

19. El Sayed SM, Ahmed SE, 2001. Socio-cultural aspects of Kalaazar among Masalit and Hawsa tribes. Ahfad J 18: 51.

20. Kumar N, Siddiqui NA, Verma RB, Das P, 2009. Knowledge about sandflies in relation to public and domestic control activities of kala-azar in rural endemic areas of Bihar. $J$ Commun Dis 41: 121-128.

21. Singh SP, Reddy DC, Mishra RN, Sundar S, 2006. Knowledge, attitude, and practices related to Kala-azar in a rural area of Bihar state, India. Am J Trop Med Hyg 75: 505-508.

22. Dizaji MB, Taghdisi MH, Solhi M, Hoseini SM, Shafieyan Z, Qorbani M, Mansourian M, Charkazi A, Rezapoor A, 2014. Effects of educational intervention based on PRECEDE model on self care behaviors and control in patients with type 2 diabetes in 2012. J Diabetes Metab Disord 13: 72.

23. Nazari M, Taravatmanesh G, Kaveh MH, Soltani A, Ghaem H, 2016. The effect of educational intervention on preventive behaviors towards cutaneous leishmaniasis at Kharameh city in 2014. Shiraz E-Medical J 17: e39957.

24. Tafti MHD, Forghani H, Moghadam MHB, Khani $P$, Noorbala MT, Mohammadi S, 2016. A survey on effect of health education on health volunteer performance and knowledge in prevention of cutaneous leishmaniasis in Yazd. J Pakistan Assoc Dermatol 21: $27-32$.

25. Chomel BB, 2008. Control and prevention of emerging parasitic zoonoses. Int Journal Parasitology 38: 1211-1217.

26. Feinstein L, Sabates R, Anderson TM et al., 2006. What are the Effects of Education on Health. Proceedings of the Copenhagen Symposium "Measuring the Effects of Education on Health and Civic Engagement".

27. Zhou M, Brown D, 2015. Educational learning theories. Education Open Text Books.1. Dalton, GA: Dalton State college. Available at: https://oer.galileo.usg.edu/education-textbooks/1. Accessed December 2018. 